\title{
Case-control study of prescribed fenoterol and death from asthma in New Zealand, 1977-81
}

\author{
N Pearce, J Grainger, M Atkinson, J Crane, C Burgess, C Culling, H Windom, R Beasley
}

\begin{abstract}
A previous New Zealand case-control study of asthma deaths in the 5-45 year age group during 1981-3 found that prescription of fenoterol (by metered dose inhaler) was associated with an increased risk of death in patients with severe asthma. One major criticism of this study was that drug data for the cases and controls came from different sources. A new case-control design has been used to evaluate the same hypothesis, with a different set of asthma deaths, the same source for drug information being used for both cases and controls. This depended on identifying deaths from asthma during 1977-81 from national mortality records, and ascertaining which patients from those who died had been admitted to a major hospital for asthma during the 12 months before death. The study was confined to this subgroup, which accounted for about $20 \%$ of all asthma deaths in the areas served by a major hospital. For each of the eligible patients who died four age matched controls were selected from patients admitted to hospital for asthma during the year that the death occurred who had also had an admission for asthma in the previous 12 months. For the 58 cases and 227 control subjects information on prescribed drugs was collected from the hospital records relating to the previous admission. The odds ratio of asthma death in patients prescribed inhaled fenoterol was 1.99 (95\% confidence interval 1.12-3.55, $p=0.02$ ). As in the previous study, subgroups defined by markers of chronic asthma severity were also considered. The inhaled fenoterol odds ratio was $2 \cdot 98(95 \%$ CI 1.15-7.70, p = 0.02 ) in patients prescribed three or more categories of asthma drugs, 3.91 (95\% CI $1.79-8.54, p<0.01$ ) in patients with a previous admission for asthma in the past 12 months, and $5 \cdot 83(95 \%$ CI 1.62-21.0, p = 0.01 ) in patients prescribed oral corticosteroids at the time of admission. In patients with the most severe asthma (defined by a previous admission for asthma during the past 12 months and prescribed oral corticosteroids at time of admission) the inhaled fenoterol odds ratio was 9.82 (95\% CI $2 \cdot 23-43.4$, p $<0.01)$. These findings add further support to the hypothesis that inhaled fenoterol increases the risk of death in patients with severe asthma.
\end{abstract}

A recent New Zealand case-control study, ${ }^{1}$ conducted by our group, tested the hypothesis that the unsupervised self administration of fenoterol by inhalation increases the risk of death from asthma. This hypothesis arose primarily from epidemiological evidence linking the sale of fenoterol to the epidemic of deaths from asthma that New Zealand has experienced since the late $1970 \mathrm{~s}^{12}$ and experimental evidence that fenoterol is a less selective beta ${ }_{2}$ agonist than salbutamol, the most commonly used beta agonist. ${ }^{3}$ The possible mechanisms of action remain to be clarified, but several potential mechanisms are apparent; these depend on whether the association is with long term use of fenoterol or use in the acute attack. Long term use may be associated with tachyphylaxis, as was suggested with isoprenaline, ${ }^{4}$ or with increases in airway hyperresponsiveness following beta agonist treatment, ${ }^{5}$ which may lead to more severe asthma. Repeated self administration of high doses of a longer acting and less selective beta ${ }_{2}$ agonist during an acute attack could result in delay in seeking medical advice, ${ }^{6}$ hypokalaemia, ${ }^{7}$ and adverse cardiac effects, ${ }^{3}$ particularly when hypoxaemia is present. ${ }^{8}$ Hypoxaemia may be made worse because beta agonists may disturb ventilation-perfusion relationships. ${ }^{9}$

The previous study related to the period August 1981-July 1983, and compared the prescribed drug treatment of patients who died of asthma with that of patients with severe asthma who did not die. The findings were consistent with the hypothesis that inhaled fenoterol increases the risk of death in patients with severe asthma. We could not, however, exclude all possible sources of bias, particularly as information on prescribed asthma drugs was obtained from different sources for the cases and controls. We have now examined the hypothesis further in a study of deaths from asthma in New Zealanders aged 5-45 years during 1977-81. Information on drugs prescribed for asthma has been obtained from the same sources for both cases and controls, the major potential source of bias in the previous study thus being avoided.

\section{Methods}

SELECTION OF SUBJECTS

Cases The potential cases comprised all patients aged 5-45 years who died from asthma in New Zealand during the period January 1977-July 1981, and who had been admitted for asthma to a major hospital during the 12 
months before death. The study was confined to those aged 5-45 years as before, ${ }^{1}$ as death from asthma is a reasonably clearcut diagnosis in this age range. ${ }^{10}$ Asthma deaths (ICD code 493) were identified from registrations at the National Health Statistics Centre. For each death the records of hospitals to which the patient was likely to have been admitted in an acute attack were then searched to identify any admission for asthma in the previous 12 months. If such an admission was identified the death was included in the study, and the admission closest to the date of death was used. The study was based on the same major hospitals that we used in the previous study, with the exception of Dunedin Public Hospital, for which ethical approval to examine the records was not obtained. As before, admissions to smaller hospitals were not considered.

Controls For each case potential controls, matched for age within five years, were selected at random from patients discharged from the same hospital with the diagnosis of asthma in the year in which the death occurred. The admission records for each potential control were then examined to determine whether the patient had had a previous hospital admission for asthma during the 12 months before the admission under consideration. If such an admission was found the patient was included as a control. For each case the first four controls meeting this criterion were selected. If sufficient controls could not be obtained the acceptable age range was widened to 10 years. For seven cases with an admission to hospitals in Auckland, Christchurch, or Hamilton insufficient controls were available and 22 of their controls were selected from another hospital in the same area. For all cases and controls the admission was considered to have been primarily for asthma, as indicated by the discharge coding.

\section{INFORMATION ON PRESCRIBED DRUGS}

For both cases and controls information on prescribed drugs for self administration was extracted from records relating to the previous adinission-that is, the admission within the 12 months before death for the cases and the corresponding prior admission for the control subjects. The number of hospital admissions for asthma during the 12 months prior to the admission under consideration (a marker of chronic asthma severity) was also ascertained from hospital notes.

We noted the prescribed asthma drugs at the time of admission as recorded in the admission notes and accident and emergency department notes and in the general practitioner's letter. Prescribed medication át the time of discharge was recorded from the admitting officer's discharge notes, the discharge letter, and the discharge prescription. We could not obtain the data "blind," but the research workers were instructed to record all drug information from these sources. When more than one record was available from a particular source (for example, in the admission notes) the record with the most complete drug information was used.

The data forms were copied and all informa- tion that identified cases and controls was deleted. Two members of the study team (CB and JC) then made a blind assessment of the drugs at admission and discharge. In one case and six controls no information was available on the drugs at discharge, and they were assumed to be the same as the drugs at admission. Information from subsequent chest clinic and outpatient visits was available for some cases and controls, but this was relatively incomplete. Thus, unless otherwise specified, all findings refer to drugs prescribed at discharge.

As in the previous study, the possibility of confounding or effect modification by severity was assessed by considering various subgroups defined by markers of chronic severity: (1) prescription of three of more categories of asthma drugs (oral or aerosolised beta agonists, nebulised beta agonists, theophyllines, sodium cromoglycate or inhaled corticosteroids, oral corticosteroids); (2) a hospital admission for asthma during the previous 12 months (that is, in the 12 months before the admission when the prescribed medication was recorded); (3) prescription of oral corticosteroids. When discharged most patients were taking several drugs, including oral corticosteroids. Thus we considered it most appropriate to define chronic severity in terms of the drugs being prescribed at the time of admission. As before, the main drug treatment of interest (fenoterol and other asthma drugs) related to the drugs prescribed at discharge.

\section{DATA ANAL YSIS}

The Mantel-Haenszel procedure ${ }^{11}$ was used to calculate odds ratios and test based confidence intervals (CI), ${ }^{12}$ and Rothman's adaptation of this procedure ${ }^{13}$ was used to perform a matched analysis. Logistic regression ${ }^{14}$ was also used to calculate odds ratios adjusted for age, gender, ethnicity, and other potential confounders.

\section{Results}

Death registrations were identified from National Health Statistics Centre records for 366 New Zealand residents with a recorded address and aged 5-45 years who died from asthma (ICD code 493) during January 1977July 1981 (four deaths of individuals not resident in New Zealand and eight deaths in patients with no recorded address were not considered). Of these, $73(20 \%)$ were in the Dunedin area or areas served by smaller hospitals (fig). On the basis of previous work, ${ }^{1}$ we expected that about a quarter of the remaining 293 deaths would have occurred in people without any previous hospital admission. Thus we expected to find hospital records relating to about 220 deaths. The search of hospital records actually identified records for 214 patients who had died. Of these, 30 had died more than one hour after arrival at a hospital. As in the previous study, these were excluded because the focus of the study was on self administered asthma drugs (two patients who died within an hour of arrival were not excluded). A further 117 patients had not had an 


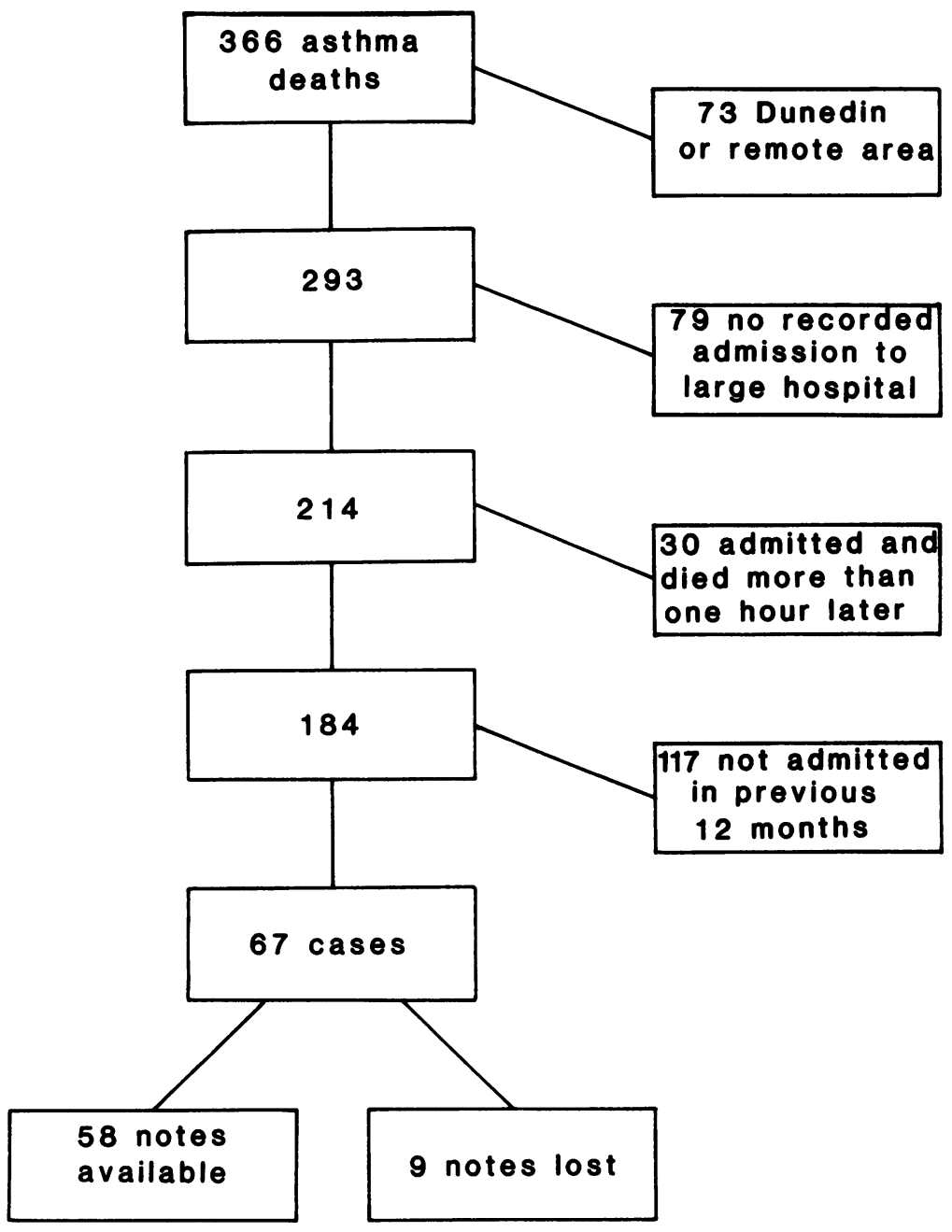

Reasons for exclusion and numbers of deaths excluded.

admission for asthma in the 12 months before death. Of the remaining 67 eligible cases, the relevant notes were found for $58(87 \%)$. For each case four matched controls were selected, with the exception of three cases for which sufficient controls could not be obtained. The study thus concerned a total of 58 cases and 227 matched controls.
The case group was $45 \%$ male and $62 \%$ European, and had a mean age of 23.9 years. The control group was $36 \%$ male, and $68 \%$ European, and had a mean age of 23.2 years. The mean time between the previous admission and the next event (either death or the next admission) was 0.34 year for cases and 0.23 year for controls. When a matched analysis was performed, the fenoterol odds ratio estimates were very similar to the crude estimates. Similarly, when the fenoterol odds ratio estimates were adjusted for age, gender, ethnic group, date of event (death or admission), and date of previous admission the results were virtually identical to the crude estimates. The crude estimates are therefore presented.

Table 1 shows the odds ratios of asthma death associated with drugs prescribed at discharge. With the exception of oral corticosteroids, there was little evidence of differences between cases and controls for any asthma medications other than inhaled fenoterol. In many instances it was difficult to determine from the hospital records whether oral corticosteroids had been prescribed as a continuous or a short course. The data for oral corticosteroids thus refer to any prescribed oral corticosteroids (continuous, short course, or unknown regimen).

The odds ratio of asthma death was 1.93 in patients prescribed fenoterol by metered dose inhaled and 1.97 in patients prescribed fenoterol by nebuliser. In the previous study there were concerns about the completeness of the nebuliser data, since the drug information was from different sources for cases and controls. This concern did not apply in the current study, and so we considered it appropriate to pool the metered dose inhaler and nebuliser data in further analyses. The overall odds ratio for inhaled fenoterol was 1.99.

In contrast to the previous study, there were some differences in the inhaled fenoterol odds ratios between males ( 26 cases, 82 controls: odds ratio $2 \cdot 77,95 \%$ CI $1 \cdot 13-6 \cdot 79)$ and females ( 32 cases, 145 controls: odds ratio $1 \cdot 53,95 \%$ CI $0 \cdot 71-3 \cdot 31$ ), and between Europeans ( 36 cases,

Table 1 Prescribed drug treatment at discharge, markers of chronic severity, and the relative risk of asthma death

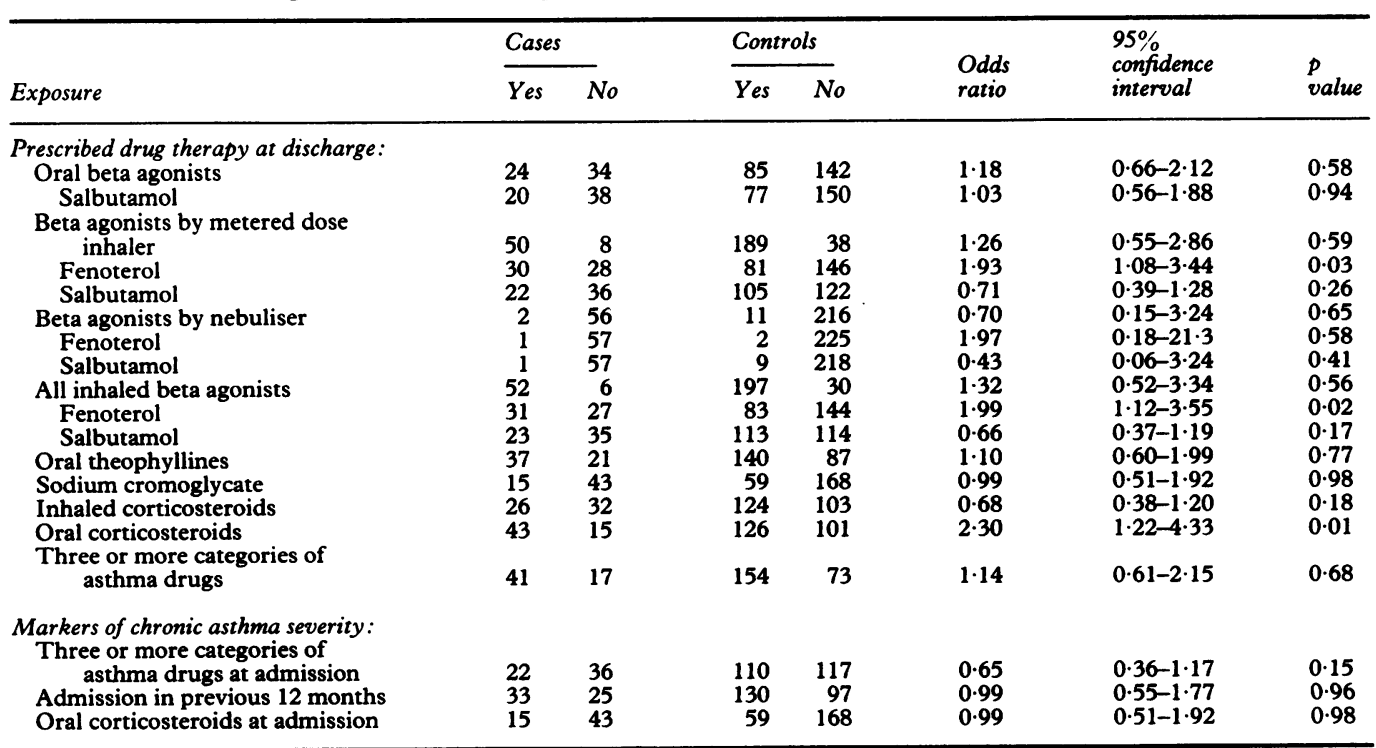


Table 2 Prescribed inhaled fenoterol at discharge and the relative risk of asthma death: findings in subgroups defined by markers of chronic severity

\begin{tabular}{|c|c|c|c|c|c|c|c|c|}
\hline \multirow[b]{3}{*}{ Subgroup } & & \multicolumn{4}{|c|}{ Prescribed inhaled fenoterol } & \multirow{3}{*}{$\begin{array}{l}\text { Odds } \\
\text { ratio }\end{array}$} & \multirow{3}{*}{$\begin{array}{l}95 \% \\
\text { confidence } \\
\text { interval }\end{array}$} & \multirow{3}{*}{$\begin{array}{l}p \\
\text { value }\end{array}$} \\
\hline & & \multicolumn{2}{|c|}{ Cases } & \multicolumn{2}{|c|}{ Controls } & & & \\
\hline & & Yes & No & Yes & No & & & \\
\hline \multicolumn{9}{|c|}{ Three or more categories of asthma drugs at admission: } \\
\hline $\begin{array}{l}\text { Yes } \\
\text { No }\end{array}$ & & $\begin{array}{l}15 \\
16\end{array}$ & $\begin{array}{r}7 \\
20\end{array}$ & $\begin{array}{l}46 \\
37\end{array}$ & $\begin{array}{l}64 \\
80\end{array}$ & $\begin{array}{l}2.98 \\
1.73\end{array}$ & $\begin{array}{l}1 \cdot 15-7 \cdot 70 \\
0.81-3.71\end{array}$ & $\begin{array}{l}0.02 \\
0 \cdot 16\end{array}$ \\
\hline \multicolumn{9}{|c|}{ Admission in previous 12 months: } \\
\hline $\begin{array}{l}\text { Yes } \\
\text { No }\end{array}$ & & $\begin{array}{r}22 \\
9\end{array}$ & $\begin{array}{l}11 \\
16\end{array}$ & $\begin{array}{l}44 \\
39\end{array}$ & $\begin{array}{l}86 \\
58\end{array}$ & $\begin{array}{l}3.91 \\
0.84\end{array}$ & $\begin{array}{l}1.79-8.54 \\
0.34-2.09\end{array}$ & $\begin{array}{r}<0.01 \\
0.70\end{array}$ \\
\hline \multicolumn{9}{|c|}{ Oral corticosteroids at admission: } \\
\hline $\begin{array}{l}\text { Yes } \\
\text { No }\end{array}$ & & $\begin{array}{l}12 \\
19\end{array}$ & $\begin{array}{r}3 \\
24\end{array}$ & $\begin{array}{l}24 \\
59\end{array}$ & $\begin{array}{r}35 \\
109\end{array}$ & $\begin{array}{l}5.83 \\
1.46\end{array}$ & $\begin{array}{l}1.62-21.0 \\
0.74-2.89\end{array}$ & $\begin{array}{l}0.01 \\
0.27\end{array}$ \\
\hline $\begin{array}{l}\text { Admission in } \\
\text { previous } 12 \\
\text { months }\end{array}$ & $\begin{array}{l}\text { Three or more } \\
\text { categories of } \\
\text { asthma drugs } \\
\text { at admission }\end{array}$ & & & & & & & \\
\hline $\begin{array}{l}\text { Yes } \\
\text { No }\end{array}$ & $\begin{array}{l}\text { Yes } \\
\text { Yes }\end{array}$ & $\begin{array}{r}13 \\
2\end{array}$ & $\begin{array}{l}5 \\
2\end{array}$ & $\begin{array}{l}28 \\
18\end{array}$ & 49 & $\begin{array}{l}4.55 \\
0.83\end{array}$ & $\begin{array}{l}1.55-13.4 \\
0.10-63\end{array}$ & 0.01 \\
\hline $\begin{array}{l}\text { No } \\
\text { Yes }\end{array}$ & $\begin{array}{l}\text { Yes } \\
\text { No }\end{array}$ & 2 & 6 & $\begin{array}{l}18 \\
16\end{array}$ & $\begin{array}{l}15 \\
37\end{array}$ & $\begin{array}{l}0.83 \\
3.47\end{array}$ & $0.10-6.83$ & 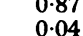 \\
\hline No & No & 7 & 14 & 21 & 43 & 1.02 & $0.36-2.93$ & 0.97 \\
\hline $\begin{array}{l}\text { Admission in } \\
\text { previous } 12 \\
\text { months }\end{array}$ & $\begin{array}{l}\text { Oral cortico- } \\
\text { steroids at } \\
\text { admission }\end{array}$ & & & & & & & \\
\hline Yes & Yes & 11 & 2 & 14 & 25 & $9 \cdot 82$ & $2.23-43.4$ & $<0.01$ \\
\hline No & Yes & 1 & 1 & 10 & 10 & 1.00 & $0.06-18 \cdot 3$ & 1.00 \\
\hline Yes & No & 11 & 9 & 30 & 61 & $2 \cdot 49$ & $0.94-6.55$ & 0.07 \\
\hline No & No & 8 & 15 & 29 & 48 & 0.88 & $0.33-2.35$ & 0.80 \\
\hline
\end{tabular}

155 controls: odds ratio $1 \cdot 20,95 \%$ CI $0 \cdot 58$ 2.50 ) and non-Europeans ( 22 cases, 72 controls: odds ratio $5 \cdot 20,95 \%$ CI $1.94-14 \cdot 0$ ). More consistent with the previous study were the substantial differences in the inhaled fenoterol odds ratios between subjects aged less than 20 years ( 22 cases, 87 controls: odds ratio $4.02,95 \%$ CI $1.57-10.3)$ and those aged 20 years or more ( 36 cases, 140 controls: odds ratio $1 \cdot 33,95 \%$ CI $0 \cdot 64-2 \cdot 78)$.

Cases and controls were similar with respect to markers of chronic asthma severity (table 1), with odds ratios of asthma death of 0.65 for three or more categories of asthma drugs at admission, 0.99 for an admission in the previous 12 months, and 0.99 for prescribed oral corticosteroids at admission. These markers were used to assess the potential for con- founding or effect modification by chronic severity (table 2 ). The inhaled fenoterol odds ratio was 2.98 in patients prescribed three or more categories of asthma drugs, 3.91 in patients with a previous admission for asthma during the past 12 months, and 5.83 in patients prescribed oral corticosteroids at the time of admission. In patients who had both been admitted to hospital with asthma in the past 12 months (before the admission under consideration) and been prescribed oral corticosteroids at the time of admission the inhaled fenoterol odds ratio was $9 \cdot 82$.

As a check for possible bias we performed an analysis using only the drugs prescribed at admission, with no consideration of drugs at discharge. The inhaled fenoterol odds ratio was 1.72 overall, and $3 \cdot 57,3 \cdot 10,16 \cdot 59$, and 14.00

Table 3 Prescribed drug treatment at discharge and the relative risk of asthma death: findings in subgroups defined by markers of chronic severity

\begin{tabular}{|c|c|c|c|c|}
\hline \multirow[b]{2}{*}{$\begin{array}{l}\text { Prescribed drugs } \\
\text { at discharge }\end{array}$} & \multicolumn{4}{|c|}{ Odds ratios (and $95^{\circ}$ o confidence intervals) in subgroups defined by markers of chronic severity } \\
\hline & $\begin{array}{l}\text { Three or more } \\
\text { categories of drugs } \\
\text { at admission }\end{array}$ & $\begin{array}{l}\text { Admission in } \\
\text { previous year }\end{array}$ & $\begin{array}{l}\text { Oral corticosteroids } \\
\text { at admission }\end{array}$ & $\begin{array}{l}\text { Admission in } \\
\text { previous year and } \\
\text { oral corticosteroids } \\
\text { at admission }\end{array}$ \\
\hline $\begin{array}{c}\text { Oral beta agonists } \\
\text { Salbutamol }\end{array}$ & $\begin{array}{l}1.40 \\
0.56-3.54 \\
1.31 \\
0.51-3.35\end{array}$ & $\begin{array}{l}1.04 \\
0.47-2.32 \\
0 \cdot 88 \\
0 \cdot 38-2 \cdot 02\end{array}$ & $\begin{array}{l}0.50 \\
0.14-1.72 \\
0.57 \\
0 \cdot 16-2.00\end{array}$ & $\begin{array}{l}0.64 \\
0 \cdot 17-2 \cdot 46 \\
0.71 \\
0 \cdot 18-2 \cdot 75\end{array}$ \\
\hline $\begin{array}{l}\text { Inhaled beta agonists } \\
\text { Fenoterol } \\
\text { Salbutamol }\end{array}$ & $\begin{array}{l}1 \cdot 87 \\
0 \cdot 23-15 \cdot 2 \\
2.98 \\
1 \cdot 15-7 \cdot 70 \\
0.38 \\
0 \cdot 14 \quad 1.01\end{array}$ & $\begin{array}{l}4 \cdot 17 \\
0 \cdot 62-28 \cdot 3 \\
3 \cdot 91 \\
1 \cdot 79-8 \cdot 54 \\
0 \cdot 35 \\
0 \cdot 16-0.78\end{array}$ & $\begin{array}{l}1 \cdot 30 \\
0 \cdot 14-12 \cdot 1 \\
5 \cdot 83 \\
1 \cdot 62-21 \cdot 0 \\
0 \cdot 18 \\
0 \cdot 04 \quad 0.79\end{array}$ & $\begin{array}{l}1 \cdot 77 \\
0 \cdot 19-16 \cdot 6 \\
9 \cdot 82 \\
2 \cdot 23-43 \cdot 4 \\
0 \cdot 09 \\
0 \cdot 01-0.55\end{array}$ \\
\hline Oral theophyllines & $\begin{array}{l}1 \cdot 19 \\
0 \cdot 37-3 \cdot 87\end{array}$ & $\begin{array}{l}1.06 \\
0.47-2.38\end{array}$ & $\begin{array}{l}5 \cdot 21 \\
0 \cdot 75-36 \cdot 1\end{array}$ & $\begin{array}{l}4 \cdot 14 \\
0 \cdot 53-32 \cdot 1\end{array}$ \\
\hline Sodium cromoglycate & $\begin{array}{l}0.86 \\
0.29-2.56\end{array}$ & $\begin{array}{l}1.06 \\
0.45-2.51\end{array}$ & $\begin{array}{l}1.09 \\
0.26-4.58\end{array}$ & $\begin{array}{l}1 \cdot 16 \\
0.25-5.32\end{array}$ \\
\hline Inhaled corticosteroids & $\begin{array}{l}0.49 \\
0.19-1.27\end{array}$ & $\begin{array}{l}0.54 \\
0.25-1.17\end{array}$ & $\begin{array}{l}0.66 \\
0.20-2.13\end{array}$ & $\begin{array}{l}0.35 \\
0 \cdot 10-1 \cdot 29\end{array}$ \\
\hline Oral corticosteroids & $\begin{array}{l}8 \cdot 24 \\
1 \cdot 42-47 \cdot 8\end{array}$ & $\begin{array}{l}1.90 \\
0.82-4.37\end{array}$ & $\begin{array}{l}1 \cdot 59 \\
0 \cdot 18-14 \cdot 2\end{array}$ & $\begin{array}{l}3 \cdot 42 \\
0 \cdot 17-67 \cdot 9\end{array}$ \\
\hline
\end{tabular}


respectively in the four subgroups of chronic severity defined in table 3.

In general, other antiasthma drugs did not seem to increase the risk of death disproportionately in patients with severe asthma (table 3 ). In contrast to the previous study, however, increased odds ratios were observed for oral corticosteroids and for oral theophyllines in some subgroups. When subjects prescribed inhaled fenoterol were deleted from the analysis (to remove the interaction between the effects of fenoterol and oral corticosteroids), the odds ratios for oral corticosteroids at discharge were: 1.84 overall, and $2.93,0.91,0.26$, and 0.78 in the four chronic severity subgroups defined in table 3 . When the analysis was adjusted (by the Mantel-Haenszel method ${ }^{11}$ ) for oral corticosteroids at discharge the inhaled fenoterol odds ratios were 1.85 overall, and $2 \cdot 61,3 \cdot 76,5 \cdot 89$, and 9.31 in the four chronic severity subgroups.

\section{Discussion}

There are now three New Zealand case-control studies, each using different sources of data, indicating that inhaled fenoterol increases the risk of death in patients with severe asthma. The fenoterol odds ratio estimate of 1.99 in the current study for patients with a hospital admission for asthma during the previous 12 months is consistent with the estimates of $2 \cdot 16$ in our previous national case-control study ${ }^{1}$ and 3.00 in the small Auckland case-control study. ${ }^{15}$ The patterns of findings in the patients with the most severe asthma are also similar in the three studies.

The larger inhaled fenoterol odds ratios in males and in non-Europeans in the current study are inconsistent with the results of our previous study. Further investigation would be warranted, particularly as the epidemic appears to have been more severe in non-Europeans. ${ }^{16}$ A more consistent finding is that the increased risk of death associated with fenoterol was particularly strong in those aged less than 20 years. The reason for this remains to be clarified, though it could be due to either a greater tendency to overuse (or use inappropriately) inhaled beta agonists in young people or a reduced response to cardiac beta stimula- $_{1}$ tion with increasing age. ${ }^{17}$

The study design used here has some important differences from that of our previous casecontrol study. ${ }^{1}$ The current study was restricted to cases and controls with a previous hospital admission for asthma during the 12 months before death (for the cases) or the admission matched to the death (for the controls). Thus the study is restricted to about $20 \%$ of the asthma deaths in the areas served by a major hospital during 1977-81. This restriction was applied in part because hospital admission and discharge records were the only readily available data source. A more important reason, however, was that in the previous casecontrol study the increased risk of death associated with fenoterol was virtually confined to patients with severe asthma, as identified by a hospital admission for asthma during the previous 12 months.

The most important feature of the current study is that the information on prescribed drugs was obtained from hospital records in an identical manner for cases and controls, and was assessed blind. The initial recording of prescribed medication from hospital records could not be performed blind, but the recording process was very comprehensive and all relevant information was extracted from the case notes.

We must emphasise that this study examined prescribed medication at the time of a hospital admission on average three to four months before death or the admission of interest, and that no information on actual drug use was available. If our hypothesis concerns a mechanism depending on long term use, then the regular prescribed medication is the factor of interest. For other possible mechanisms the self administered medication actually used in the final attack would be relevant. Given that this is not available, the regular prescribed medication is an acceptable surrogate, as asthmatic patients are very likely to use their prescribed medication in an acute attack. There is no reason to believe that the small proportion of patients who failed to take medication in an acute attack would differ substantially according to the beta agonist that was prescribed. Thus the major concern is that the use of this surrogate measure could produce a bias towards 1.0 in the observed odds ratio. ${ }^{18}$ Despite this concern the regular prescribed medication may be the most valid available measure, because changes in drug treatment at the time of the final attack could lead to bias. These issues are readily understood in the context of a clinical trial in which data are analysed according to the "intention to treat" principle.

As in our previous case-control study, an important methodological issue is the potential for confounding by severity. A previous New Zealand study ${ }^{15}$ has showed many similarities between patients admitted to hospital with asthma and patients who die of asthma. Major differences in average severity between the case and control groups in this study thus appear unlikely, particularly as both groups had a hospital admission for asthma followed by another attack (resulting in hospital admission or death) during the subsequent 12 months. In addition, cases and controls were very similar with regard to various markers of chronic asthma severity. Despite the problems of obtaining a "definitive" marker of chronic severity, these markers do have the merit that they are based on information that would have been available to the physician at the time the beta agonist was prescribed. Information not available to the physician at that time is not relevant to the issue of confounding by severity. If the overall increased fenoterol odds ratio had been due to confounding by chronic severity, this would be expected to decrease as the analysis was increasingly restricted to subjects with more severe chronic asthma. Instead, the inhaled fenoterol odds ratio increased substantially. This indicates that our 
findings are not due to confounding by chronic asthma severity.

In contrast to the previous study, increased odds ratios were observed for oral corticosteroids and for oral theophyllines in some subgroups. Both of these categories of drugs were prescribed on discharge to most patients with severe asthma, and the confidence limits for the odds ratios are accordingly very wide. The overall odds ratio for oral theophyllines, however, was only $1 \cdot 10$, and the increased odds ratios in the most severe subgroups could have been due to chance.

The findings for oral corticosteroids on discharge are puzzling, and are inconsistent with those in our previous study. ${ }^{1}$ They were not of strong a priori interest, in contrast with the fenoterol findings. They do, however, raise the possibility of differences in acute severity (but not chronic severity) between cases and controls, a hypothesis that is consistent with the tendency for the differences to diminish in the most severe subgroups (table 3 )..But there was little evidence of differences in oral corticosteroid treatment at discharge between cases and controls when the fenoterol effect was removed, and adjustment for oral corticosteroids at discharge resulted in only minor changes to the estimates for the fenoterol effect. Furthermore, there was little evidence of differences for other markers of acute severity or for markers of chronic severity (including oral corticosteroids on admission), which is of greater relevance. ${ }^{19}$ Thus the findings regarding inhaled fenoterol seem unlikely to be due to confounding by severity. Instead, the data indicate that inhaled fenoterol increases the risk of death in patients with severe asthma.

Our previous case-control study has been criticised for using markers of chronic asthma severity rather than markers of the severity of the final attack..$^{21}$ As noted above, however, both studies have examined prescribed medication. When we are considering confounding therefore attention should be focused on risk factors that may be associated with prescription of fenoterol. ${ }^{19}$ The severity of the final attack is irrelevant in this context, as this usually occurred several months after prescribing occurred. In fact, for all of the hypothesised mechanisms the severity or the life threatening nature of the final attack could be a result of using fenoterol. Thus controlling for the severity of the final attack is at best irrelevant, and may lead to serious bias. Once again, these issues are most readily understood in the context of a clinical trial analysed according to the "intention to treat" principle.

In summary, the findings of the current study are consistent with the hypothesis that inhaled fenoterol increases the risk of death in patients with severe asthma. Our previous study produced similar findings, but the possibility of information bias could not be excluded owing to the collection of drug information from different sources for cases and controls. This potential bias is avoided by the study design used here. No single case-control study may be regarded as conclusive, because not all sources of bias can be definitely excluded. The findings presented here, however, add support to the hypothesis that the unsupervised self administration of fenoterol by inhalation in patients with severe asthma increases the risk of death.

Partial salary support for JC comes from the Medical Research Council of New Zealand. We wish to thank the Asthma Foundation of New Zealand for financial assistance; the superintendents of the hospitals visited for their help and cooperation in providing access to the hospital admission records; the staff of the medical records departments for their help in obtaining records; Gail de Boer, Jo Rutledge, and other staff of the National Health Statistics Centre for their help with data on asthma deaths and hospital admissions; and Steve Marshall for assistance with data management. We also thank Dr Rod Jackson and Professor Robert Beaglehole for their comments on the draft manuscript.

1 Crane J, Pearce NE, Flatt A, et al. Prescribed fenoterol and death from asthma in New Zealand, 1981-1983: casecontrol study. Lancet 1989;i:917-22.

2 Jackson RT, Beaglehole R, Rea HH, Sutherland DC Mortality from asthma: a new epidemic in New Zealand. Br Med J 1982;285:771-4.

3 Crane J, Burgess C, Beasley R. A comparison of the cardiovascular and hypokalaemic effects of inhaled sal-
butamol, fenoterol and isoprenaline. Thorax 1989;44: butamol, fenoterol and isoprenaline. Thorax 1989;44: $136-40$

4 Conolly ME, Davies DS, Dollery CT, George CF. Resistance to beta-adrenoceptor stimulants (a possible explanation for the rise in asthma deaths). Br J Pharmacol 1971; 43:389-402.

5 Vathenen AS, Knox AJ, Higgins BG, Britton JR, Tattersfield AE. Rebound increase in bronchial responsivenes after treatment with inhaled terbutaline. Lancet 1988; i:554-8.

6 Sears MR. Patients at risk for dying of asthma: New Zealand experience. J Allergy Clin Immunol 1987;80:477-81.

7 Haalboom JRE, Deenstrom M, Struyvenberg A. Hypokalaemia induced by inhalation of fenoterol. Lance 1985;i:1125-7.

8 Collins JM, McDevitt DG, Shanks RG, Swanton JG. The cardiotoxicity of isoprenaline during hypoxia. $\mathrm{Br}$ Pharmacol 1969;36:35-45.

9 Aggestrup S, Henriksen L, Rygg IH, Lauridsen P. The cardiovascular and respiratory effects of fenoterol in patients after open-heart surgery. Cardiovasc Surg 1980 21:409-16.

10 Sears MR, Rea HH, de Boer G, et al. Accuracy of certification of deaths due to asthma: a national study. $A m J$ Epidemiol 1986;124:1004-11.

11 Mantel N, Haenszel W. Statistical aspects of the analysis of data from retrospective studies of disease. J Natl Cancer data from retrospective

12 Miettinen OS. Estimability and estimation in case-referent studies. Am J Epidemiol 1976;103:226-35.

13 Rothman KJ. Modern epidemiology. Boston: Little, Brown, 1986:258.

14 Harrell F. The logist procedure. In: $S A S$ supplemental library user's guide. Cary, North Carolina: SAS Institute, 1986: $269-93$.

15 Rea HH, Scragg R, Jackson R, Beaglehole R, Fenwick J, Sutherland DC. A case-control study of death from asthma. Thorax 1986;41:833-9.

16 Sears MR, Rea HH, Beaglehole R, et al. Asthma mortality in New Zealand: a two-year national study. NZ Med J 1985; 98:271-5.

17 Kendall MJ, Woods KL, Wilkins MR, Worthington DJ. Responsiveness to beta adrenergic receptor stimulation: the effects of age are cardioselective. Br J Clin Pharmacol 1982;14:821-6.

18 Copeland KT, Checkoway HA, McMichael AJ, Holbrook $\mathrm{RH}$. Bias due to misclassification in the estimation of relative risk. Am J Epidemiol 1977;105:488-95.

19 Pearce N, Crane J, Burgess C, Beasley R, Jackson R. Fenoterol and asthma mortality [letter]. Lancet 1989;i: 1196-7.

20 O'Donnell TV, Holst P, Rea HH, Sears MR. Fenoterol and fatal asthma [letter]. Lancet 1989;i:1070-1.

21 Buist AS, Burney PGJ, Feinstein AR, et al. Fenoterol and fatal asthma [letter]. Lancet 1989;i:1071. 